\title{
Dairy cows with prolonged calving seek additional isolation
}

\author{
M. V. Rørvang, ${ }^{1}$ M. S. Herskin, and M. B. Jensen \\ Department of Animal Science, Aarhus University, Blichers Allé 20, 8830 Tjele, Denmark
}

\begin{abstract}
In modern calving facilities, dairy cows either calve in a group pen or are moved to a separate individual pen when calving is imminent. In practice, cows are often moved too close to calving, which poses a health risk to cow and calf. Thus, a need exists for new calving facility designs and management practices that better align with the motivations of the cow. This study examined dairy cow preferences for individual calving pens by offering 3 different levels of isolation (tall and narrow, low and wide, and tall and wide) by analyzing the association between precalving behavior, choice of degree of isolation, and the progress of calving. The hypotheses were that cows would prefer the highest level of isolation when giving birth, and that calving in a high level of isolation would be associated with less restlessness and a shorter calving duration. Contrary to these hypotheses, no specific preference between degrees of isolation or difference in calving behavior in the different calving pens was found. However, cows experiencing a longer calving duration chose to calve in the most secluded calving pen (tall and wide). These results cannot determine cause and effect, but may suggest that interactions between motivation for isolation seeking and calving behavior exist.
\end{abstract}

Key words: isolation seeking, maternal behavior, calving site selection, cow preferences

\section{INTRODUCTION}

The transition from dry to lactating is a high-risk period for dairy cows. Calving itself places high demands physically but is also painful (Maineau and Manteca, 2011), and the transition to lactation is associated with a high risk of disease (Atkinson, 2016). In recent years, farm size has increased (Barkema et al., 2015) and the high number of calvings require surveillance, which can be challenging in modern dairy production, where it is recommended that cows calve in separate

Received September 12, 2016.

Accepted December 27, 2016.

${ }^{1}$ Corresponding author: Maria.VilainRorvang@anis.au.dk calving facilities that they are introduced into when calving is imminent (Marcussen and Laursen, 2007; Rushen et al., 2008). The use of individual calving pens is recommended based on the known preference of the preparturient cow to seek isolation as calving approaches (Proudfoot et al., 2014a,b); in some countries, calving in individual pens has been adopted by law (Ministry of Environment and Food of Denmark, 2014) to ensure an undisturbed parturition in a clean pen. Furthermore, allowing the cow to separate herself from the group when motivated to do so before calving may also contribute to good animal welfare. In practice, however, the management of preparturient cows is not simple. If cows are moved based on predicted calving date they may occupy the individual calving pen for several days, but when cows are moved late in the first stage of calving this may prolong the second stage of calving (Proudfoot et al., 2013), which may lead to uterine infections, calving complications, and other production related diseases. Hence, it is a management challenge to introduce cows to a clean, secluded, and undisturbed calving pen in time, and this requires intensive surveillance of the cows. Farmers could potentially benefit from on-line monitoring (e.g., accelerometers or rumination collars) of behavioral and physical changes occurring before calving. However, reduced rumination (Schirmann et al., 2013), increased number of lying bouts (Miedema et al., 2011; Jensen, 2012), and reduced vaginal temperature (Ouellet et al., 2016) did not occur until the last few hours before calving, and moving of the cow based on these signs may be too late in practical farming. An alternative option is the development of new cow motivation-based systems, where cows voluntarily move into individual calving pens when motivated to separate from the group. To develop such a system, knowledge of the cow's preferences for calving pen design is a prerequisite to stimulate isolation from the herd before calving. Campler et al. (2014) showed that cows avoid calving on a rubber surface as compared with sand, and Proudfoot et al. (2014b) found that cows prefer to be secluded at calving. Thus, a certain degree of isolation and provision of a soft and non-slip surface in individual calving pens may increase the motivation of dairy cows to enter. 
However, at present, the preferred degree of isolation is not known. In addition, potential effects of being able to isolate before giving birth on the calving behavior of dairy cows have not been examined.

By providing cows access to individual calving pens with soft bedding and offering different levels of isolation, we investigated dairy cows' preference regarding degree of isolation at calving. Additionally, we investigated precalving behavior, use of the opportunity to isolate, and the progress of calving in relation to the final choice of degree of isolation. We hypothesized that cows would prefer the highest degree of isolation when giving birth, as this isolation opportunity would seclude the cow the most while still offering minimal opportunity for visual and tactile contact to cows in the group pen. Moreover, we hypothesized that calving in the most secluded pen would be associated with less restlessness and a shorter duration of calving than when the calves were born in pens with lower degrees of isolation.

\section{MATERIALS AND METHODS}

The experiment took place at the Danish Cattle Research facility at Aarhus University (Foulum, Denmark) between September 2014 and March 2015.

\section{Animals, Housing, and Management}

Initially, the study included 49 multiparous Danish Holstein cows, which was the number of cows calving in the resident barn during the study period. Prior to calving, these cows were allocated to 9 groups of 5 to 6 cows according to expected calving date [insemination date $+280 \mathrm{~d}$ (Danish mean number of gestation days in Holstein cows; Marcussen and Laursen, 2007)] to reach approximately the same number of days between successive calvings within groups. All cows were of the resident herd at Aarhus University, AU-Foulum, Tjele, Denmark, and were group housed in a cubicle barn before the experimental start, and thus familiar with other cows in their group. A block consisted of 3 groups, each moved to the group pen of their experimental section (Figure 1) approximately $2 \mathrm{wk}$ before the first expected calving in that group. Cows were thus blocked according to expected calving date. All group pens had deep straw bedding, and 6 individual feed bins (bin width = $75 \mathrm{~cm}$, Jyden, Vemb, Denmark) and 2 automatic selffilling water cups (model 2177-4010, Jyden).

Each group pen was connected to 2 maternity units (Figure 1 and 2), each of which was subdivided into 3 interconnected individual calving pens between which a cow could move freely via a rubber-floored alley [Kura Flex, Kraiburg, Tittmoning, Germany; a 19-mm-thick, pebbled-surface rubber mat with 5 -mm studs on the lower side (24 mm including 5-mm studs)]. All individual calving pens had 1.3 -m high sides made from tubular metal bars on 3 sides and a feed trough (model 1318-8210, Jyden) on the fourth (facing the outer wall). A 1.8-m-high light gray, plastic barrier (low-density polyethylene compound, $10 \mathrm{~mm}$ thick) covered 2 pen sides. The third pen side, facing the group pen, was partly covered by either $50 \%$ (height $\times$ width) a tall and narrow, $1.8 \times 1.5 \mathrm{~m}$ barrier $(\mathrm{A})$; a low and wide, $1.0 \times 2.5 \mathrm{~m}$ barrier $(\mathrm{B})$; or covered $75 \%$ by a tall and wide, $1.8 \times 2.5 \mathrm{~m}$ barrier $(\mathrm{C})$. This resulted in 3 different individual calving pens in each maternity unit (Figure 2). These dimensions were chosen to compare effects of height or width or both. The uncovered part of the third side of each individual calving pen allowed some visual and tactile contact with animals in the group pen. The allocation of barriers $\mathrm{A}, \mathrm{B}$, or $\mathrm{C}$ to each individual calving pen was balanced to account for possible side bias of the cows (allocation indicated in Figure 1). In all individual calving pens, $30 \mathrm{~cm}$ of deep barley straw bedding covered the floor facing the group pen $(3 \times 3 \mathrm{~m})$, and a rubber mat covered the alley part facing the outer walls $(1.5 \times 9 \mathrm{~m}$; Figure 1$)$. This arrangement ensured that cows did not lie in the alley between the 3 individual calving pens. In each maternity unit, water was available for ad libitum intake from 2 self-filling water cups (identical to the ones in the group pen).

Clean straw was added daily to the group pens by the barn staff. In the maternity unit, fresh straw was added daily after removal of manure and any soiled straw, and the rubber alley was cleaned daily. Before introduction of a new cow, the maternity unit was cleaned out (i.e., all straw and manure removed) and fresh straw added. Bedding quality of each individual calving pen was evaluated daily before manure removal and scored according to a 5-point scale developed prior to the experiment: (0) dry, no feces or urine; (1) moist, less than 3 spots with feces; (2) slightly wet, some dry straw and more than 2 spots with feces; (3) wet, mainly wet straw and feces; (4) very wet, only wet straw, feces and urine spread over the whole pen (median: 1, range: 0-4). Barn staff used this measure as a reference to minimize differences in bedding quality between individual calving pens and maternity units.

Within each experimental section, cows were moved individually to one of the 2 maternity units at least 3 $\mathrm{d}$ before expected calving (mean $\pm \mathrm{SD}: 5.8 \pm 2.7 \mathrm{~d}$ ) or if signs of imminent calving (i.e., enlarged udder, soft ligaments, attentive toward abdomen or udder, licking the udder) appeared before this time. After calving, each cow and her calf remained in the maternity unit for 72 to $96 \mathrm{~h}$. 

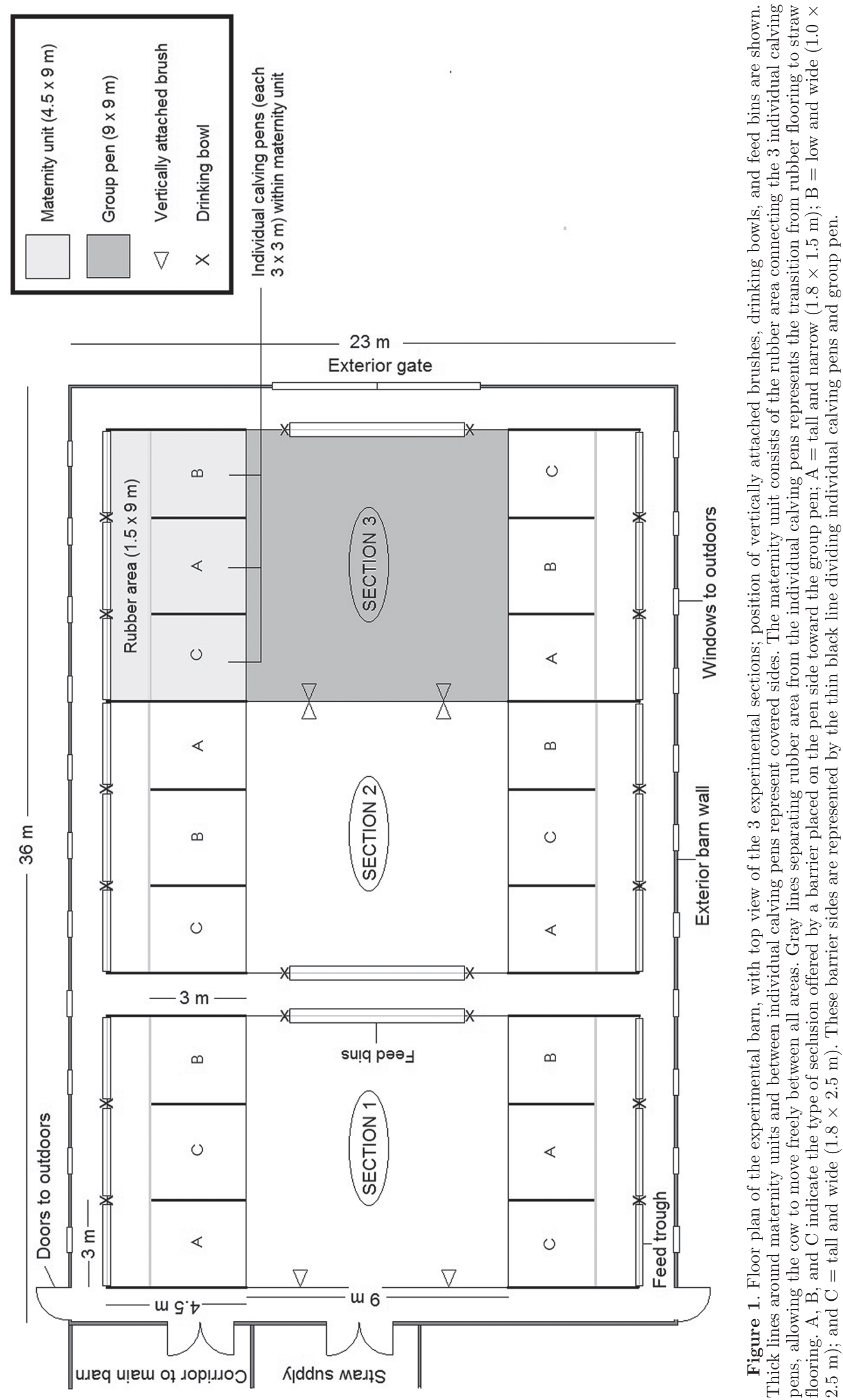


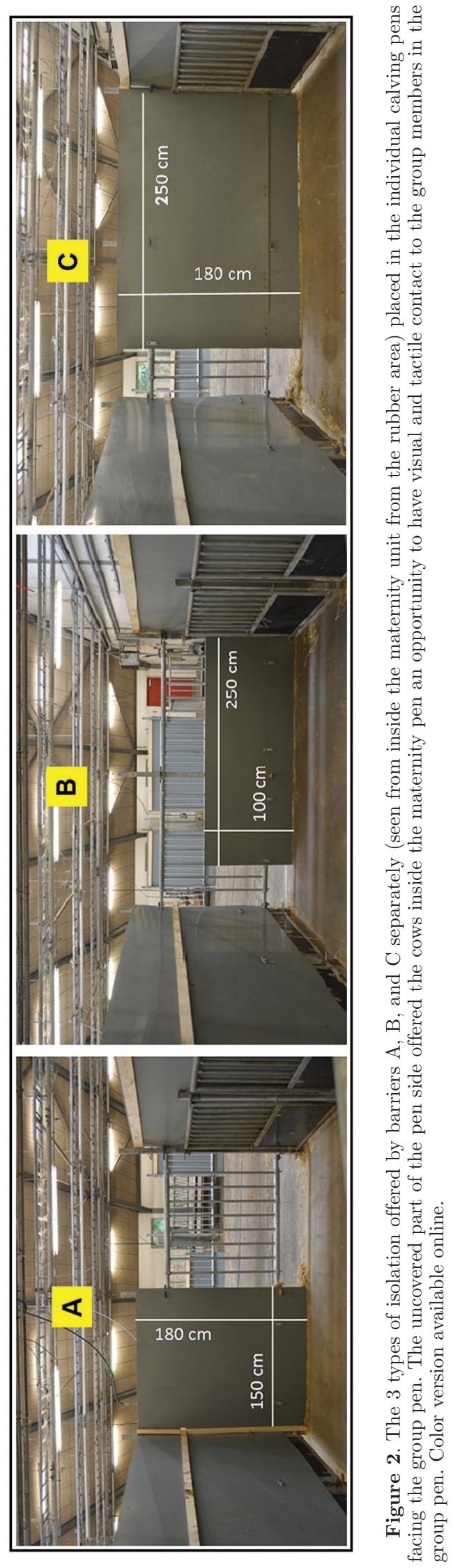

Delivery of a calf was assisted if the calf was not born within $4 \mathrm{~h}$ after the appearance of the amniotic sac. Calvings were supervised using video surveillance cameras (described below), enabling the barn staff to observe the appearance of the amniotic sac or the legs of a calf without disturbing the cows.

Cows were excluded from the experiment if they calved in the group pen $(\mathrm{n}=3)$, if they spent less than $3 \mathrm{~d}$ in the maternity unit before calving $(\mathrm{n}=1)$, if they had to be moved between barn sections due to lack of space $(\mathrm{n}=2)$, if they were diagnosed by the herd veterinarian with milk fever, mastitis, or retained placenta within $24 \mathrm{~h}$ of calving $(\mathrm{n}=4)$, or if their calving was assisted $(n=2)$, as all of these situations could have influenced the choice of the cow. Thus, 37 cows were included in the analysis; 21 cows entering their second parity, 14 entering their third parity, and 2 older cows.

\section{Behavioral Observations and Variables}

Behavior was monitored via black-and-white digital video cameras (model TVCCD-624, Monacor, Bremen, Germany) mounted $3.5 \mathrm{~m}$ above each individual calving pen. An experienced technician monitored and stored the video recordings and an experienced observer collected all behavioral data. To avoid bias, the observer collecting the data was unable to distinguish between the different individual calving pens (i.e., A, B, or C) from the video recordings. During the $24 \mathrm{~h}$ before birth of the calf, cow behavior was recorded continuously according to an ethogram (Table 1). To evaluate the cow's choice of calving pen at the moment of calving, the location and orientation of the cow inside the calving pen was recorded when the hips of the calf were fully expelled. This measure adds information about the chosen level of isolation, as well as to what extent the visual or tactile contact with the group was favored or not (Table 1). If half of a cow's body was in one half of a calving pen (as defined in Table 1), the placement of the head of the cow determined the outcome. In addition, the location, posture, and orientation of the cow were determined (Table 1). The individual calving pen, where the calf was born, was scored as the final choice of calving site. As contractions are among the early signs of second stage labor (Noakes et al., 2001), the second stage of labor was, per definition, initiated at the first visible rhythmical abdominal contraction bout (while the cow was lying) and finalized when the hips of the calf were fully expelled (Proudfoot et al., 2013; Table 1). The frequency of lying bouts, number of contractions, and number of times the cow moved between individual calving pens were summarized.

Cows were gait-scored when entering and exiting the experimental sections. The scoring was done by 2 
experienced observers according to a 5-point scoring system (Thomsen et al., 2008). No cows were scored as obviously lame (above score 3 ) and the median score was 1 (range $=1-3$ ). All cows were weighed by use of an automatic scale (Danvægt, Hinnerup, Denmark). The cows weighed on average $673(\mathrm{SD}=59) \mathrm{kg}$ when entering the experiment and $646(\mathrm{SD}=53) \mathrm{kg}$ when leaving.

\section{Statistical Analysis}

Based on Shapiro-Wilk normality test and visual assessment of histograms, normality of the recorded variables could not be assumed as data were skewed. All variables were thus analyzed by nonparametric tests using the base system of the statistical software $\mathrm{R}(\mathrm{R}$ version 3.1.2.; $\mathrm{R}$ Core Team, 2014) and results evaluated using a significance level of $5 \%$.

\section{Behavior 24 Hours Before Calving}

Preference for calving site was analyzed by Chisquared test. When analyzing whether the duration of the second stage of labor or time spent inside the final choice of calving pen were affected by the final choice of individual calving pen, a Kruskal-Wallis test was used (Siegel and Castellan, 1988). A post hoc analysis was conducted using a Wilcoxon rank sum test to compare cows choosing either individual calving pen A or B (the lowest level of isolation, 50\%) to cows choosing individual calving pen $\mathrm{C}$ (the highest level of isolation, $75 \%$ ). To analyze if the choice of individual calving pen affected the orientation of the cow at calving, the association of these categorical variables was analyzed by a Chi-squared test. When analyzing if cow orientation at calving affected the duration of the second stage of labor, a Wilcoxon rank sum test was used.

Table 1. Ethogram of recorded location, posture, and behavior of the dairy cows during $24 \mathrm{~h}$ before calving and at the time of calving

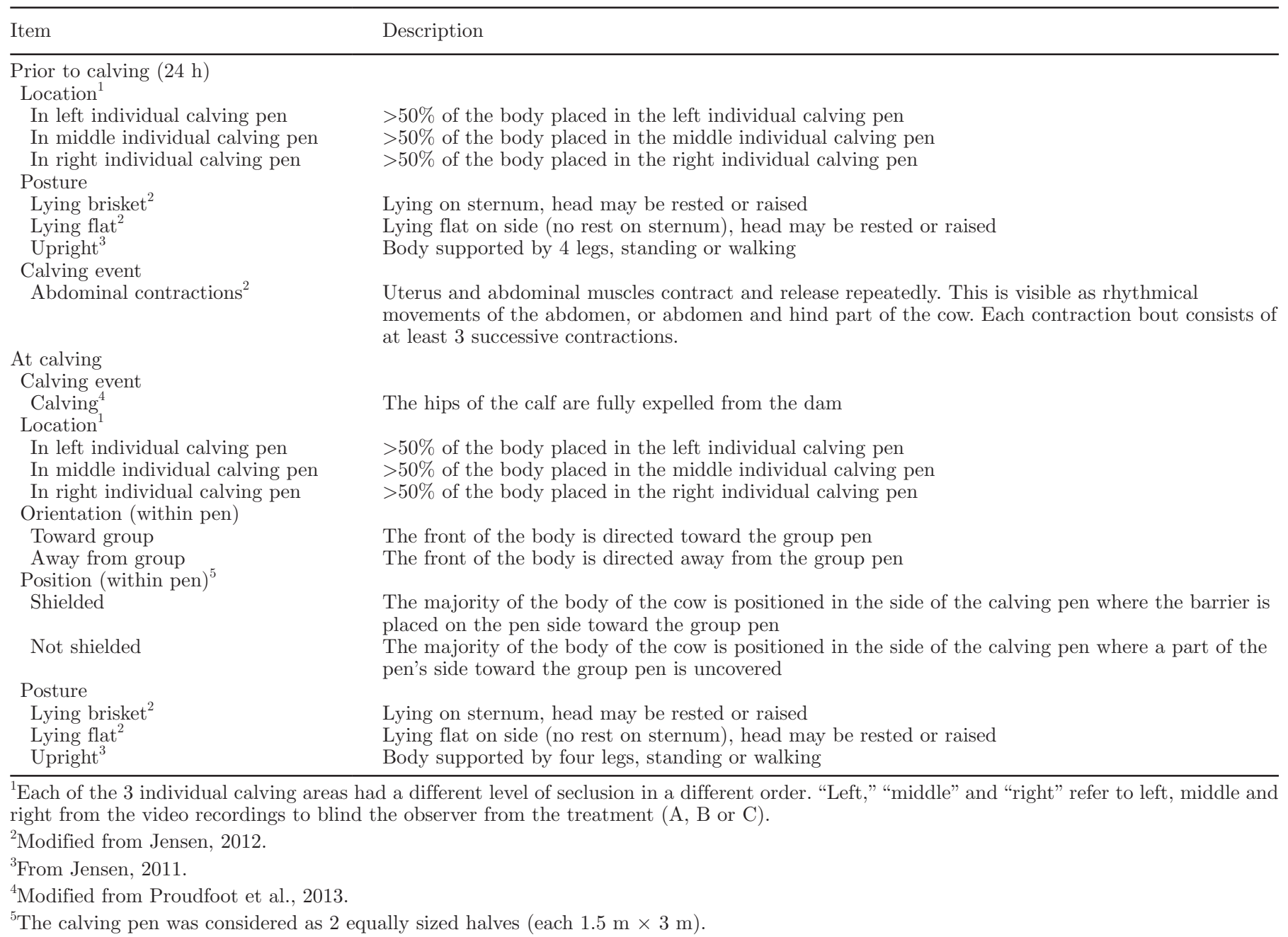




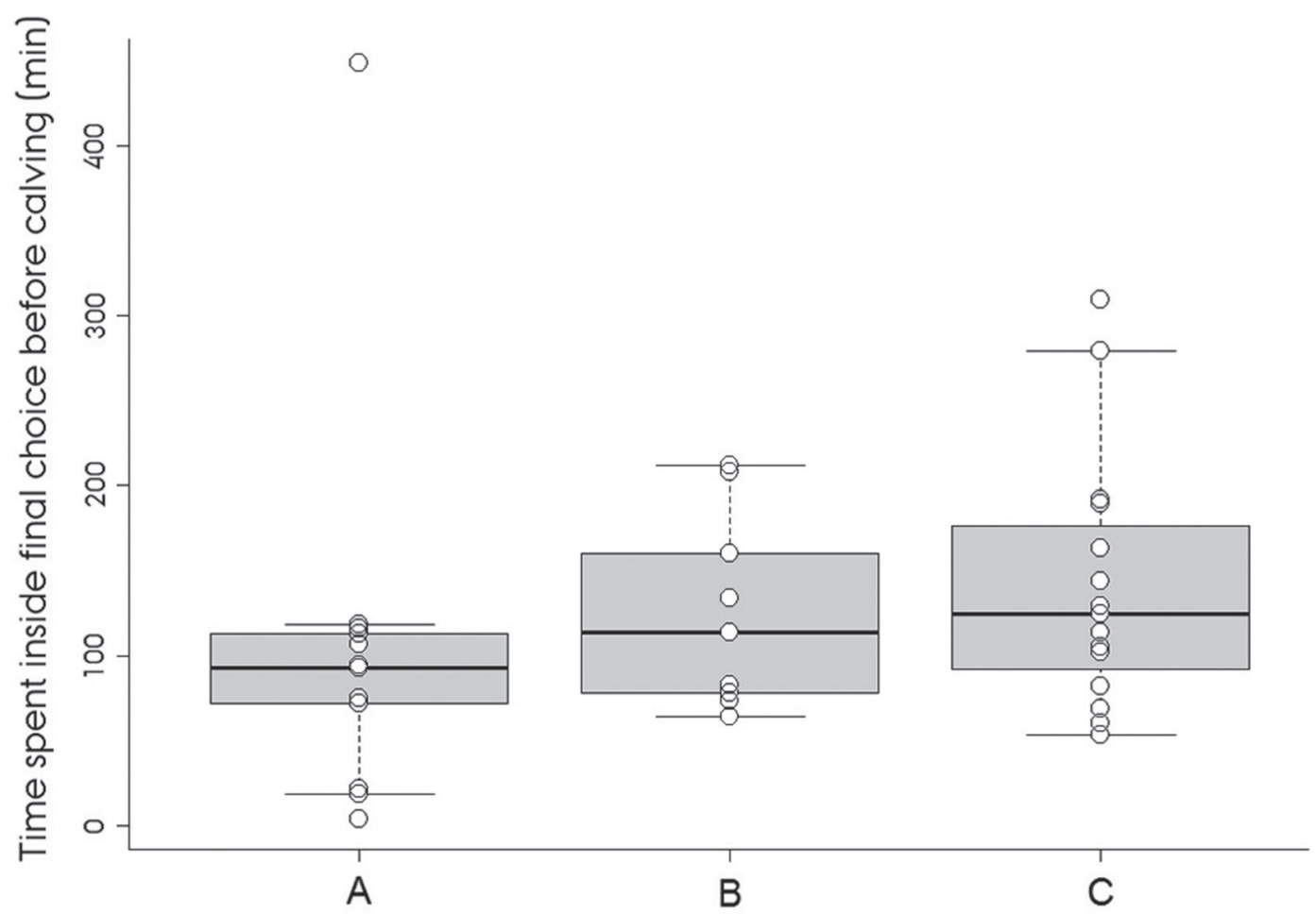

Final choice of individual calving pen design

Figure 3. Box plot of the duration of time ( $\min )$ spent in the individual calving pen finally chosen (from entering an individual calving pen the last time until calving) for the 3 individual calving pens A (tall and narrow), B (low and wide), and C (tall and wide) during the final $24 \mathrm{~h}$ before calving. Whiskers indicate maximum and minimum, box represents the 25 and $75 \%$ quartiles, and the thick black line indicates the median.

\section{Effects of Changing Calving Area During the Second Stage of Labor}

Twelve cows changed individual calving pen after the first visible abdominal contractions (definition in Table 1). These cows were compared with the 25 cows not changing individual calving pen after the first abdominal contractions in a post hoc analysis. A Wilcoxon rank sum test (two-sided) was used to compare the 2 groups with respect to the variables: duration of second stage of labor, number of lying bouts, number of contractions, and number of individual calving pen changes.

\section{RESULTS}

\section{Behavior During 24 Hours Before Calving}

The cows showed no significant preference for a specific individual calving pen (number of cows giving birth in individual calving pen $\mathrm{A}, \mathrm{B}$, and $\mathrm{C}$ were 13,9 , and 15 , respectively; $\left.\chi^{2}=1.51 ; \mathrm{df}=2 ; P=0.38\right)$. No difference between the 3 individual calving pens was found for the duration of time spent in the individual calving pen where the calf was born $\left(\chi^{2}=3.50 ; \mathrm{df}=2\right.$;
$P=0.17$; Figure 3$)$. We found no effect of final choice on the duration of the second stage of labor $\left[\left(\chi^{2}=0.53\right.\right.$; $\mathrm{df}=2 ; P=0.77 ; 108.44(\mathrm{SD}=66) \mathrm{min}]$.

We ran a post hoc analysis comparing cows choosing 1 of the 2 individual calving pens with the lowest level of isolation (A or $\mathrm{B}$ ) with cows choosing the individual calving pen with the highest level of isolation (C). Results of the analysis showed that the cows choosing the higher level of isolation had a significantly longer duration of second stage labor $(\mathrm{w}=44 ; P=0.047$; Figure 4). Twenty out of the 37 cows faced away from the group when calving (cows facing away/all cows: $\mathrm{A}=7 / 11, \mathrm{~B}=5 / 11, \mathrm{C}=8 / 15)$. For these cows, the particular individual calving pen $(\mathrm{A}, \mathrm{B}$ or $\mathrm{C})$ did not affect their orientation at calving $\left(\chi^{2}=2.20 ; \mathrm{df}=2\right.$; $P=0.33)$. Furthermore, cow orientation did not affect the duration of the second stage of labor $(\mathrm{w}=190 ; P$ $=0.56)$.

\section{Effects of Changing Individual Calving Pen After Initiation of Contractions}

Twelve cows were observed having contractions before entering the individual calving pen where the 


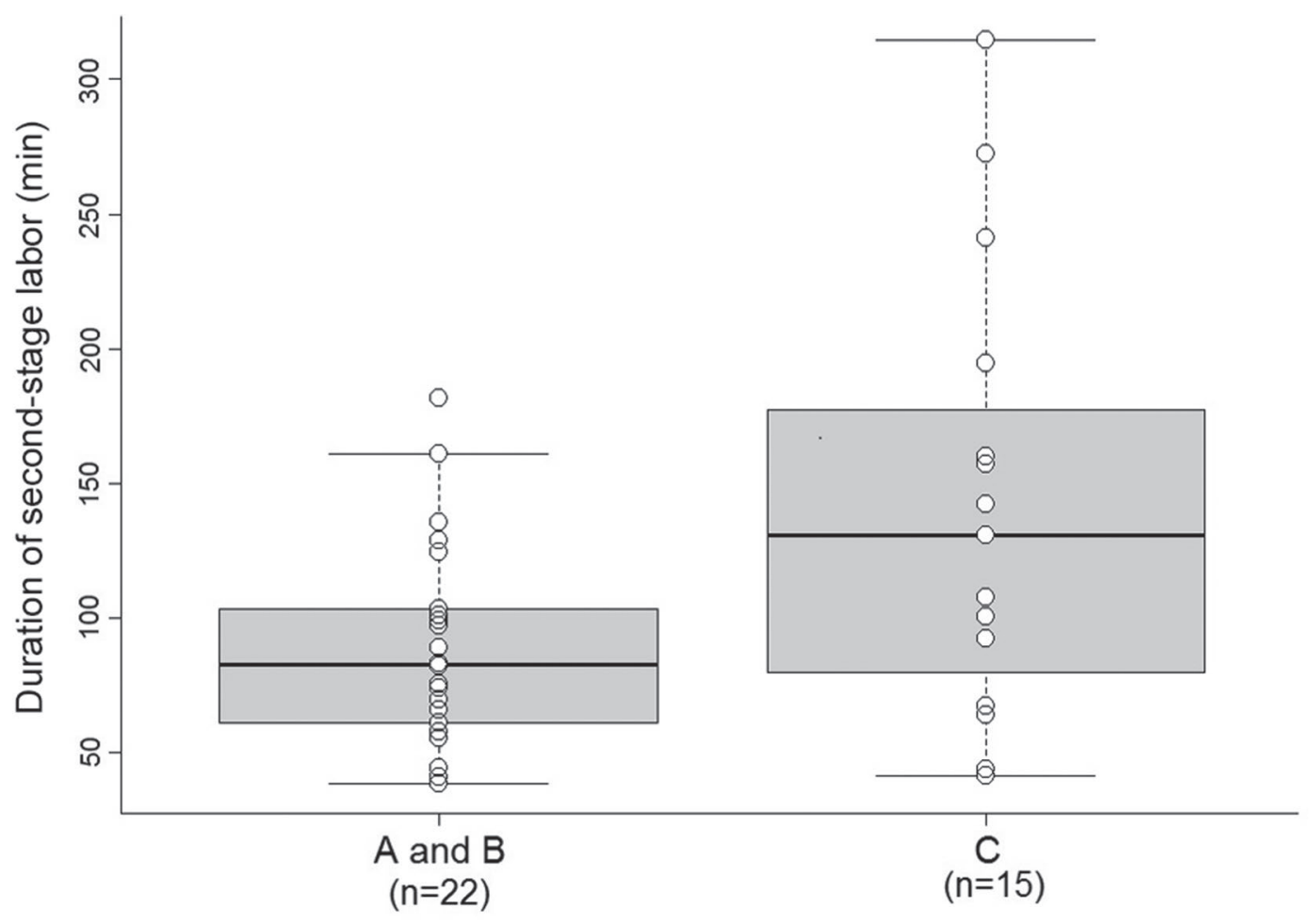

Final choice of individual calving pen design

Figure 4. Box plot illustrating the post hoc analysis comparing the duration of the second stage of labor of cows choosing individual calving pen A or B (50\% isolation) to cows choosing individual calving pen C (75\% isolation). Whiskers indicate maximum and minimum, box represents the 25 and $75 \%$ quartiles, and the thick black line indicates the median.

calf was born (final choice), and these cows had significantly longer second stage labor compared with cows not changing individual calving pen after initiation of contractions (Table 2). These 12 cows did not change individual calving pen more often when calculated for the $24 \mathrm{~h}$ before calving, but had a significantly higher number of lying bouts and contractions (Table 2) when compared with cows not changing their preference during the second stage of labor. Moreover, 7 out of these 12 cows changed from individual calving pen $\mathrm{A}$ or $\mathrm{B}$ to $\mathrm{C}$, whereas only 2 changed from $\mathrm{A}$ or $\mathrm{C}$ to $\mathrm{B}$ and 3 from $\mathrm{B}$ or $\mathrm{C}$ to $\mathrm{A}$.

\section{DISCUSSION}

This study examined aspects of calving site selection in dairy cows by allowing preparturient cows to choose between individual calving pens offering different types (in term of height, width or both) and levels of isolation (in term of percentage coverage), and by examin-

Table 2. Calving duration (min), number of changes cows made between individual calving pens, number of lying bouts, and number of contractions during the last $24 \mathrm{~h}$ before calving ${ }^{1}$

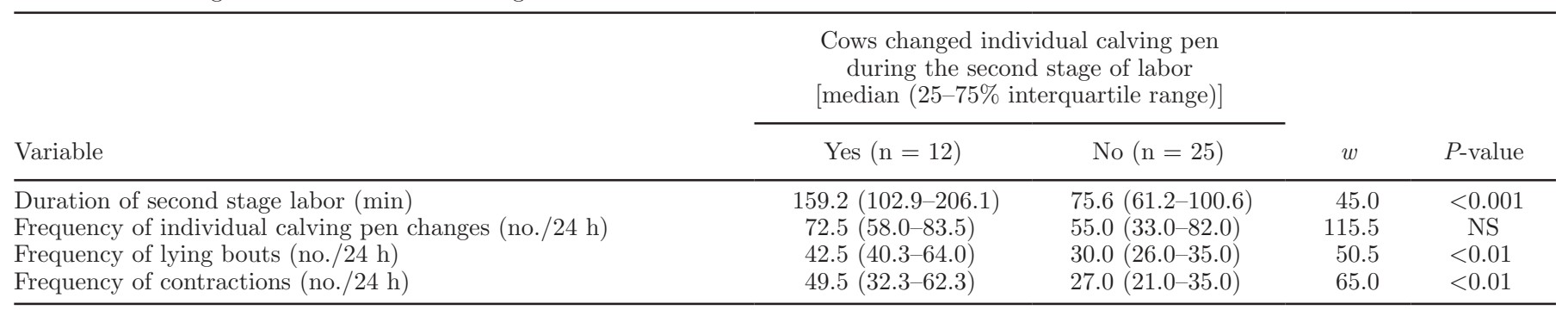

${ }^{1}$ Data are shown for cows changing individual calving pen during the second stage of labor and cows not changing individual calving pen during the second stage of labor, respectively. Statistics from the Wilcoxon rank sum test are shown in column $w$ with corresponding $P$-value. In the tests of these variables, smaller values of $w$ are more significant. 
ing possible consequences of these choices in terms of calving behavior. Based on data from 37 calvings, no preference for a specific individual calving pen design or for a specific isolation level (50 vs. $75 \%$ ) could be found. Furthermore, no difference between calving behavior in the different pens was found. However, cows experiencing a longer calving duration (longer second stage labor) gave birth in the most isolated individual calving pen, and cows that changed individual calving pen after the initiation of the first rhythmical abdominal contractions (onset of second stage labor) had a longer calving duration, more contractions, and a higher number of lying bouts as compared with cows not changing pen after the onset of second stage labor. These results provide new information specifically useful for future design of calving pens for dairy cows and for the understanding of possible effects of being able to isolate before giving birth.

We found no preferences for a specific calving pen design (A, B, or $\mathrm{C}$ ), and no preference for a specific level of isolation ( $\mathrm{A}$ and $\mathrm{B}$, or $\mathrm{C}$ ) in the preparturient dairy cows. We hypothesized that most cows would calve in the individual calving pen with the highest level of isolation or the most secluded design, but the results did not confirm this. It is, however, possible that dairy cows show a preference for a high degree of isolation, but that the present design of the 3 different individual calving pen barriers were not perceived as being different by the cows. For instance, the relatively low variation in the degree of isolation (from 50 to $75 \%$ ) or the short distance between the cows in the group pen and the individual calving pens may have caused this. Comparing the 3 different types of isolation, we did not find differences in periparturient behavior, nor did the 3 different types of isolation affect the orientation of the cows according to the group when calving, which may suggest that the cows did not perceive the individual calving pens as different and thus behaved alike in all cases. Under natural or seminatural conditions, cows move away from the group when calving is imminent (Lidfors et al., 1994), possibly implying that distance might play role in how cows perceive isolation. Sows have been shown to walk considerable distances to select a suitable place to give birth (Jensen, 1988, 1989), and free-ranging and wild sheep have also been shown to move away from the herd when lambing (freeranging, Alexander at al., 1990; wild, reviewed in Dwyer and Lawrence, 2005). Another interpretation, however, could be that the seclusion provided by the 3 different calving pen designs all fulfilled the motivation for isolation. Future studies, manipulating other aspects of social isolation (e.g., the distance to neighboring cows, or the opportunity for olfactory or auditory isolation) are needed to clarify these points.
Unexpectedly, the present results did not support the hypothesis that calving in the individual calving pen with the highest level of isolation was associated with less restlessness and a shorter duration of calving. In fact, all cows changed calving pen often, which may imply restlessness within the last $24 \mathrm{~h}$ before calving. This may also reflect that cows (due to the interconnected calving pens and their common feed table) could be moving alongside the feed table while feeding and, as a consequence, change calving pens without fully entering the straw area. On the other hand, giving birth in a pen offering the highest level of isolation was associated with a longer calving duration, indicating that, even though no clear preference for birth site was shown, the calving pens were not perceived as being similar. Cows having the longest calving durations chose the highest level of isolation, possibly explained by an increased level of restlessness and increased discomfort during calving. It is difficult to determine when calving becomes difficult and when it becomes more painful for the cow; however, we speculate that a prolonged calving and exhaustion adds to this. Previously, a longer calving duration has been associated with more frequent uterine contractions (Barrier et al., 2012), implying that dystonic cows are exposed to a higher level of pain from the increased number of contractions during calving (reviewed in Rushen et al., 2008), potentially leading to higher levels of restless behavior (Maineau and Manteca, 2011). Recently, a tendency of compromised cows to choose a secluded area after calving has been shown for sick cows (Proudfoot et al., 2014a), which may have been motivated by pain or discomfort. However, this possibility warrants further study involving behavioral as well as physiological and metabolic measures.

The present findings of interactions between periparturient behavior of dairy cows and their birth site selection need further investigation to clarify cause and effect. However, from a practical point of view, the present knowledge that indoor-housed preparturient cows did not show a clear choice between the 3 different types and levels of isolation, as well as the described interaction between long calving duration and the choice of the high degree of isolation, might suggest that providing dairy cows with calving pens providing $75 \%$ of isolation might be the best of the present options. What still remains uncertain, and needs further clarification before motivation-based calving facilities can be designed, is whether isolating behind a barrier is sufficiently attractive in order for a preparturient cow to move away from the group and isolate. As suggested, further studies are needed to understand what mechanisms drive isolation-seeking behavior in preparturient dairy cows. 


\section{CONCLUSIONS}

Contrary to the hypotheses, we found no preference for specific types or levels of isolation and no difference in calving behavior between dairy cows giving birth in the individual calving pens with different seclusion designs. Cows experiencing a longer calving duration gave birth in the most secluded individual calving pen ( $75 \%$ isolation), and cows that changed individual calving pen after initiation of the first rhythmical abdominal contractions had a longer calving duration, more contractions, and more lying bouts. These results cannot determine cause and effect, but suggest that interactions between motivation for isolation seeking and calving behavior exist. Before new management solutions for calving cows based on isolation-seeking behavior of the dam can be developed, further studies of the mechanisms underlying motivational changes in the hours before giving birth are needed.

\section{ACKNOWLEDGMENTS}

The authors thank Green Development and Demonstration Programme of the Danish Ministry of Food, Agriculture and Fisheries (Copenhagen, Denmark), as well as the PhD school GSST, Aarhus University, for funding. We also thank Jyden Bur A/S (Vemb, Denmark) for providing barriers and other inventory to build the experimental sections. The farm staff and the students at AU Foulum (Tjele, Denmark) helping throughout the study period are gratefully acknowledged. Last, we thank John Misa Obidah (AU Foulum) and Victor Delautre (Agrocampus Ouest, Rennes, France) for solving and assisting with practicalities of all kind throughout the study period and Rodrigo Labouriau (Aarhus University, Department of Mathematics, Aarhus, Denmark) for the statistical discussions.

\section{REFERENCES}

Alexander, G., D. Stevens, and L. Bradley. 1990. Distribution of field birth-sites of lambing ewes. Aust. J. Exp. Agric. 30:759-767.

Atkinson, O. 2016. Management of transition cows in dairy practice. In Pract. 38:229-240.

Barkema, H. W., M. A. G. von Keyserlingk, J. P. Kastelic, T. J. G. M. Lam, C. Luby, J.-P. Roy, S. J. LeBlanc, G. P. Keefe, and D. F. Kelton. 2015. Invited review: Changes in the dairy industry affecting dairy cattle health and welfare. J. Dairy Sci. 98:7426-7445.

Barrier, A. C., M. J. Haskell, A. I. Macrae, and C. M. Dwyer. 2012. Parturition progress and behaviours in dairy cows with calving difficulty. Appl. Anim. Behav. Sci. 139:209-217.
Campler, M., L. Munksgaard, M. B. Jensen, D. M. Weary, and M. A. G. von Keyserlingk. 2014. Short communication: Flooring preferences of dairy cows at calving. J. Dairy Sci. 97:892-896.

Dwyer, C. M., and A. B. Lawrence. 2005. A review of the behavioral and physiological adaptations of extensively managed breeds of sheep that favour lamb survival. Appl. Anim. Behav. Sci. 92:235260.

Jensen, M. B. 2011. The early behavior of cow and calf in an individual calving pen. Appl. Anim. Behav. Sci. 134:92-99.

Jensen, M. B. 2012. Behavior around the time of calving in dairy cows. Appl. Anim. Behav. Sci. 139:195-202.

Jensen, P. 1988. Maternal behavior and mother-young interactions during lactation in free-ranging domestic pigs. Appl. Anim. Behav. Sci. 20:297-308.

Jensen, P. 1989. Nest site choice and nest building of free-ranging domestic pigs due to farrow. Appl. Anim. Behav. Sci. 22:13-21.

Lidfors, L. M., D. Moran, J. Jung, P. Jensen, and H. Castren. 1994. Behavior at calving and choice of calving place in cattle kept in different environments. Appl. Anim. Behav. Sci. 42:11-28.

Maineau, E., and X. Manteca. 2011. Pain and discomfort caused by parturition in cows and sows. Appl. Anim. Behav. Sci. 135:241-251.

Marcussen, D., and A. K. Laursen. 2007. The Basics of Dairy Cattle Production. 1st ed. Danish Agricultural Advisory Service, National Centre, Aarhus, Denmark.

Miedema, H. M., M. S. Cockram, C. M. Dwyer, and A. I. Macrea. 2011. Behavioral predictors of the start of normal and dystocic calving in dairy cows and heifers. Appl. Anim. Behav. Sci. 132:14-19.

Ministry of Environment and Food of Denmark. 2014. Law no 520, 26/05/2010; Ministerial order number 470 of $15 / 5 / 2014$. Accessed Jan. 16, 2015. https://www.retsinformation.dk/pdfPrint. aspx?id=162875.

Noakes, D. E., T. J. Parkinson, G. C. W. England, and G. H. Arthur. 2001. Parturition and the care of parturient animals. Page 155-187 in Arthur's Veterinary Reproduction and Obstetrics. 8th ed. Saunders, Philadelphia, PA.

Ouellet, V., E. Vasseur, M. Heuwiesser, O. Burfeind, X. Maldague, and É. Charbonneau. 2016. Evaluation of calving indicators measured by automated monitoring devices to predict the onset of calving in Holstein dairy cows. J. Dairy Sci. 99:1539-1548.

Proudfoot, K. L., M. B. Jensen, P. M. Heegaard, and M. A. von Keyserlingk. 2013. Effect of moving dairy cows at different stages of labor on behavior during parturition. J. Dairy Sci. 96:1638-1646.

Proudfoot, K. L., M. B. Jensen, D. M. Weary, and M. A. von Keyserlingk. 2014a. Dairy cows seek isolation at calving and when ill. J. Dairy Sci. 97:2731-2739.

Proudfoot, K. L., D. M. Weary, and M. A. G. von Keyserlingk. 2014b. Maternal isolation behavior of Holstein dairy cows kept indoors. J. Anim. Sci. 92:277-281.

R Core Team. 2014. R: A language and environment for statistical computing. R Foundation for Statistical Computing, Vienna, Austria. Accessed Sep. 20, 2014. http://www.R-project.org/.

Rushen, J., A. M. de Passillé, M. A. G. von Keyserlingk, and D. M. Weary. 2008. The Welfare of Cattle. vol. 5. Springer, Dordrecht, the Netherlands.

Schirmann, K., N. Chapinal, D. M. Weary, L. Vickers, and M. A. G. von Keyserlingk. 2013. Short communication: Rumination and feeding behavior before and after calving in dairy cows. J. Dairy Sci. 96:7088-7092.

Siegel, S., and N. J. Castellan. 1988. Nonparametric Statistics for Behavioral Sciences. 2nd ed. McGraw Hill International Editors, New York, NY

Thomsen, P. T., L. Munksgaard, and F. A. Tøgersen. 2008. Evaluation of a lameness scoring system for dairy cows. J. Dairy Sci. 91:119-126. 